\title{
Abordagens imagético-verbais relacionadas à balança elétrica de Coulomb em livros didáticos de Física ${ }^{+*}$
}

\author{
Maxwelton Ferreira da Silva ${ }^{1}$ \\ EEEFM Ten. Lucena - SEE \\ João Pessoa - PB \\ Maria Amélia Monteiro ${ }^{2}$ \\ FACET/UFGD \\ Dourados - MS
}

\section{Resumo}

O propósito da presente pesquisa é analisar as abordagens imagéticoverbais sobre a balança elétrica de repulsão de Coulomb, em dez livros didáticos de física, utilizados no nível médio da educação básica brasileira. A análise ocorreu a partir de três categorias da taxonomia de Perales e Jiménez, a saber: o grau de iconicidade das imagens, a relação da imagem com o texto principal e as etiquetas verbais, notadamente os sentidos que essas atribuem às imagens. As categorias foram analisadas individualmente em cada livro e guiadas por três questões de pesquisa correspondentes. Como referencial teórico, nos apoiamos em pesquisas que realçam distintas possibilidades e limitações acerca do uso das imagens com finalidades educacionais, em referenciais históricos que contemplam o desenvolvimento da eletricidade e do magnetismo nos séculos XVI e XVII, além da Primeira Memória Sobre a Eletricidade e o Magnetismo, na qual Coulomb descreve os procedimentos da construção do aparato experimental da balança elétrica. As análises evidenciam que as representações imagéticas acerca da balança elétrica não reproduzem fielmente o rigor requerido pelo aparato e, mesmo àquelas categorizadas como fotografia, não mobilizam satisfatoriamente a constituição do aparato experimental. No tocante as abordagens textuais referentes à

\footnotetext{
${ }^{+}$Verbal imagetic approaches related to Coulomb's electrical balance in Physics textbooks

* Recebido: novembro de 2014. Aceito: março de 2015.

${ }^{1}$ E-mail: maxeltonf2008@gmail.com

2 E-mail: mariamonteiro@ufgd.edu.br
} 
balança elétrica de repulsão, via de regra, encontram-se desarticuladas tanto das etiquetas verbais quanto das representações imagéticas do aparato. Além disso, subestimam a própria complexidade da constituição do aparato, priorizando algumas conjecturas decorrentes de interpretações dos resultados experimentais. Concluímos então que, nos livros didáticos analisados, as representações imagético-verbais da balança elétrica de Coulomb não são adequadamente mobilizadas, no sentido de contribuir com a compreensão dos conceitos subjacente ao mencionado aparato experimental.

Palavras-chave: Balança elétrica de repulsão; Representações imagético-verbais; Análise de livros didáticos de Física.

\section{Abstract}

The purpose of this research is to analyze verbal imagetic approaches on Coulomb's eletrical balance of repulsion in ten Physics textbooks used in Brazilian High School education. The analysis was done considering three categories of Perales and Jiménez's taxonomy: the degree of iconicity of images, the relations of the image with the main text and verbal labels, and, more specifically, the meanings that these labels attach to the images. The categories were analyzed individually in each book and guided by three questions from corresponding researches. The theoretical framework consists in researches that enhance distinct possibilities and limitations regarding the use of images, notably when used with educational purposes, in historical references that include the development of electricity and magnetism in the sixteenth and seventeenth centuries, besides the First Memoir on Electricity and Magnetism, in which Coulomb described the procedures to build the experimental apparatus of the aforementioned balance. The analysis reveals that the imagetic representations on the balance do not accurately reproduce the rigor required by the apparatus, and even those categorized as photographic representations do not mobilize the constitution of the experimental apparatus. Textual approaches regarding the torsion electrical balance are usually disconnected on the verbal labels and imagetic representations of the experimental apparatus. In addition, they underestimate the complexity of the constitution of the apparatus by prioritizing some conjectures arising from interpretations of the experimental results. We conclude that the verbal imagetic representations of the Coulomb electrical balance, in 
textbooks analyzed, are not adequately mobilized in order to contribute to the understanding of the underlying concepts of the experimental apparatus that was previously mentioned.

Keywords: Eletrical balance of repulsion; Verbal imagetic representations; Analysis of Physics textbooks.

\section{Introdução}

Em diversos contextos educacionais, o livro didático de ciências tem sido um recurso amplamente utilizado por estudantes, bem como pelos professores no planejamento das suas atividades para a educação básica (CAMPANARIO, 2001). Assim, o livro didático tem presença assegurada no contexto educacional, inclusive difundindo o que grupos elegeram como pertencendo ao conhecimento oficial (APPLE, 1997). Conforme destaca Pimentel (2006), a intensa utilização do livro didático no contexto educacional brasileiro contrasta com as recomendações existentes nos documentos oficiais da educação básica, sugerindo aos professores a utilização de múltiplos recursos didáticos.

Apesar de durante décadas o livro didático de ciências ter sido isento de críticas, pesquisas tem evidenciando que aqueles são permeados pelos mais diversos anacronismos (BONAZZI; ECO, 1980). No tocante as abordagens dos livros didáticos brasileiros de ciências, constata-se que incorporam várias inconsistências, a saber: erros conceituais na área de astronomia (LANGHI; NARDI, 2007); inadequação na utilização das analogias em conteúdos da química (FRANCISCO JÚNIOR, 2009); erros relacionados a conceitos pertinentes à Teoria da Relatividade Restrita (OSTERMANN; RICCI, 2002), apenas para citar algumas.

Acerca da utilização das imagens, Gibin, Kiill e Ferreira (2009), por exemplo, analisam as representações imagéticas referentes ao conceito de equilíbrio químico, em seis livros didáticos brasileiros do nível médio de ensino. Utilizam quatro categorias da taxonomia de Perales e Jiménez (2002), a saber: a finalidade das ilustrações na sequência didática, o grau de iconicidade das ilustrações, a relação das ilustrações com o texto principal e a funcionalidade das etiquetas verbais. Constatam que poucas imagens corroboram para a compreensão dos conceitos, assumindo função meramente figurativa. Em relação ao grau de iconicidade, identificam o predomínio de fotografias e desenho esquemático com signos, que grande parte das ilustrações está sem articulação com o texto e a maioria das etiquetas verbais são nominativas.

Coutinho et al (2010) analisam o potencial didático das imagens e sua relação com a informação textual em quatro coleções didáticas de biologia, sugeridas pelo Guia do Livro Didático do Ensino Médio (2005). Apoiam-se no modelo de memória operacional e na teoria da carga cognitiva. Através de uma escolha aleatória, analisam 13,12 \% das imagens dos capítulos das coleções, as quais foram categorizadas segundo quatro aspectos relacionados ao valor didático: decorativa, representacional, organizacional e explicativa. As imagens são analisadas segundo três princípios da teoria cognitiva: coerência, sinalização e contiguidade. Poste- 
riormente, categorizadas como sem valor didático, com alta carga cognitiva ou de difícil leitura pelo aluno, com baixa carga cognitiva ou de fácil leitura pelo aluno. Os autores constatam o predomínio de imagens sem valor didático e com alta carga cognitiva, em detrimento de imagens com baixa carga cognitiva. Opinam que esta condição poderá dificultar a organização e processamento das informações na memória operacional do leitor e assim, prejudicar a aprendizagem desses.

Valladares e Palacios (2002) analisam o uso de imagens relacionadas à representação das atividades experimentais em livros didáticos de física e química destinados à educação básica espanhola. Constam que, frequentemente as imagens são utilizadas como argumento visual, na tentativa de convencer o leitor sobre a linguagem verbal. Em algumas situações, a argumentação visual é inadequada e com pouca contribuição para a aprendizagem. Além disso, usam falsas representações imagéticas de atividade experimentais para sustentarem supostas verdades científicas, concluem os autores.

Com o intuito de ampliar o entendimento sobre a utilização das imagens relacionadas a experimentos e suas articulações com os textos, analisamos as abordagens imagéticoverbais relacionadas à balança elétrica de repulsão de Coulomb, em dez livros didáticos de física, destinados ao nível médio da educação básica brasileira. A análise justifica-se pela complexidade teórica e técnica incorporada ao mencionado aparato, pelas contribuições decorrentes do manuseio daquele e também por se tratar de um experimento abordado pela maioria dos livros didáticos desse nível de ensino.

\section{A linguagem imagético-verbal}

Em diversos momentos e culturas, a imagem tem sido utilizada como registro da atividade humana, evidenciando múltiplas formas de comunicação. As imagens têm sido mobilizadas como fonte documental, a exemplo da antropologia, das artes plásticas, da história, da geografia, além de objeto de investigação quanto às interpretações na cognição, na comunicação e outras. A produção e o uso da linguagem imagética intensificaram-se com o aprimoramento dos processos gráficos, culminando com as imagens virtuais. Assim, a linguagem imagética ocupa cada vez mais espaços, antes exclusivos da linguagem verbal.

Barthes (1990) argumenta que o conteúdo informacional a partir da leitura das imagens possui natureza polissêmica, por incorporar uma cadeia de significados, alguns escolhidos pelo observador em detrimento doutros. A leitura de especificidades da imagem possibilita a interpretação de distintas mensagens, mesmo que a imagem seja única. Logo, uma imagem incorpora distintas vozes.

A partir da perspectiva anterior, é possível que uma única imagem transmita múltiplas mensagem para observadores distintos. Ou seja, a leitura das imagens requer decodificação, resultando que os significados têm fronteiras fluidas. A mensagem das imagens também poderá ser potencializada pela linguagem verbal, desde que coerentemente articuladas. 
No tocante ao papel das imagens para a aprendizagem, Belmiro (2000) opina que poderão contribuir para a superação do ritmo cansativo da leitura textual, além de possibilitarem novas leituras a partir de formas, personagens, cenários e outros. Contudo, a autora também alerta que uma ilustração sem coerência com o texto poderá suplantar o sentido daquela. Ou seja, a inserção da imagem no texto não deverá ser aleatória.

Martins, Gouvêa e Piccinini (2005) realçam a importância das imagens para mediar a compreensão das ideias científicas, por corroborarem com a inteligibilidade do texto e com a constituição dos conceitos. No entanto, Carneiro (1997) alerta que a imagem por si só, não conduz a compreensão do conceito, mas poderá mobilizar a sua compreensão. Essa mobilização não é imediata, muitas vezes requerendo o auxílio do professor no sentido do estudante perceber alguns aspectos constitutivos da imagem em análise, defende a autora. A utilização da linguagem imagético-verbal requer a superação do ímpeto de que a imagem por si só aclara a compreensão das ideias contidas no texto. Logo, para se utilizar recursos imagéticos no ensino de ciências deve-se considerar as relações histórico-culturais dos estudantes com esses recursos, alertam Silva et al (2006).

Alguns pesquisadores questionam o intenso uso das imagens nos livros didáticos de ciências, alegando que frequentemente não se articulam compativelmente com o texto. Medeiros e Medeiros (2001) alertam que as imagens poderão ocasionam problemas epistemológicos e de comunicação. Contudo, Cassiano (2002) alega que, dois terços das imagens presentes em amostra de livros didáticos de Física são imprescindíveis na explicação dos conceitos.

Pesquisadores apontam algumas funções para o uso das imagens no contexto educacional. Nos livros didáticos, Duchastel e Waller (1979) elegem três funções como prioritárias: atrativa, retentora e explicativa. Respectivamente, a primeira relaciona-se com a possibilidade de algumas imagens despertarem o interesse do aluno para um tema. A segunda relaciona-se ao prazo que a mensagem imagética perdura na mente do leitor. A terceira contempla o papel das imagens na elucidação das informações textuais.

Perales e Jiménez (2002) opinam que para as imagens contribuírem com a compreensão da linguagem textual se faz necessário que alguns fatores sejam delimitados, tais como, a relação mútua entre o texto e a imagem, a inclusão de textos específicos relacionados às imagens e a inserção de texto nas imagens. Opinam ainda que a informação textual é constituída de elementos narrativos e argumentativos, enquanto a informação imagética se mostra parcial. Logo, a imagem só é compreendida em sua totalidade quando correlacionada ao texto, devendo ser interpretada coerentemente em situações de ensino.

Visando delimitar especificidades a serem analisada nas imagens, Perales e Jiménez (2002) propõem uma taxonomia categórica das variáveis constituintes das imagens dos livros didáticos e suas relações com o texto. Nessa, a imagem é analisada quanto à função da sequência didática; o grau de iconicidade; a funcionalidade; a relação da imagem com o texto principal; as etiquetas verbais e o conteúdo científico que as fundamentam. Dessas, na presen- 
te pesquisa mobilizamos o grau de iconicidade da imagem, a relação da imagem com o texto principal e a mobilização das etiquetas verbais, especificados a seguir.

Na taxonomia de Perales e Jiménez (2002), a iconicidade refere-se ao grau de complexidade incorporado à imagem, classificadas como fotografias, as quais reproduzem o objeto ou realidade, independentemente da técnica utilizada; desenhos figurativos ou representações que imitam a realidade; desenhos figurativos mais signos, que representam ações e magnitudes inobserváveis; desenhos esquemáticos, que enaltecem as relações e desprezam os detalhes; desenhos esquemáticos mais signos, que representam ações e magnitudes não observáveis; descrições em signos normalizados, que incorporam representações homogêneas mais signos com regras sintáticas específicas. A partir de uma adaptação da escala de Moles, classificam as imagens das mais realistas a menos realistas.

$\mathrm{Na}$ relação entre a imagem e o texto principal, analisam-se as relações mútuas. Perales e Jiménez (2002) propõem três especificações na relação entre esses: conotativa, denotati$v a$ e sinóptica. Na relação conotativa, o texto reporta-se à imagem sem mencionar sua correspondência com os elementos daquela. Supõe-se que esta correspondência seja óbvia e que o leitor possa articulá-la. Na relação denotativa, o texto estabelece correspondência entre os elementos da imagem e os conteúdos abordados. Na relação sinóptica, o texto descreve correspondência entre os elementos da imagem e os conteúdos abordados, bem como as condições em que os elementos da imagem representam as relações entre os conteúdos. Assim, imagem e texto constituem uma unidade indivisível.

As etiquetas verbais são os textos acoplados as imagens, os quais poderão auxiliar ou dificultar a interpretação daquela pelo leitor. Perales e Jiménez (2002) classificam a relação da etiqueta verbal com a imagem em três categorias: sem etiquetas verbais; com etiquetas verbais nominativas, onde letras ou palavras identificam alguns elementos da ilustração e as etiquetas verbais relacionais, as quais descrevem as relações dos elementos apresentados pela imagem.

\section{A Eletricidade e o Magnetismo nos séculos XVII e XVIII}

Alguns fenômenos nomeados como elétricos durante o século XVII, já eram conhecidos na Antiguidade, apesar de neste período não fazerem conexão entre as relações causais de tais fenômenos. Dentre esses a propriedade do âmbar em atrair corpos leves depois de atritado com certos materiais. Um fenômeno magnético, também conhecido desde a Antiguidade era a atração permanentemente produzida pela magnetita nos objetos metálicos (ROLLER; ROLLER, 1957).

Até o século XVII, os estudos dos fenômenos elétricos situavam-se no campo dos fenômenos curiosos, haja vista a inexistência de aplicações práticas para aqueles (FORBES; DIJKSTERHUIS, 1963). Ao contrário dos fenômenos elétricos, os fenômenos magnéticos haviam sido bastante estudados antes do século XVII, inclusive resultando em aplicações. Os chineses, por exemplo, foram pioneiros na construção de um instrumento de orientação a par- 
tir das propriedades magnéticas dos materiais (ROLLER; ROLLER, 1957). Ao final do século XVI, Robert Norman propôs uma solução para o problema da inclinação da agulha da bússola, a qual dificultava a precisão da orientação propiciada pelo instrumento (BERNAL, 1975).

No século XIII, Petrus Peregrinus de Maricourt constatou que os imãs continuavam apresentando dois polos, mesmo após segmentado em duas partes. Peregrinus construiu um tratado sobre o magnetismo, reunindo os estudos existentes sobre a temática, associando-os as suas experiências (BERNAL, 1975).

A partir do final do século XVI, a eletricidade e o magnetismo alcançaram avanços significativos a partir das investigações de William Gilbert (1544-1603), considerado um pioneiro da modernidade sobre aquelas áreas. Em 1600, na Inglaterra, Gilbert publicou um tratado, The Magnete, no qual, além de mencionar os antigos escritos sobre os efeitos magnéticos da pedra-ímã, detalhou novos procedimentos experimentais, inclusive considerando a Terra como um grande imã esférico. Explicou o comportamento da bússola sobre a superfície terrestre, e concluiu que o campo magnético apresenta intensidade máxima nos polos. Gilbert constatou ainda que, quando alguns materiais eram atritados, apresentavam propriedades semelhantes às do âmbar e distingui o fenômeno da atração associado ao efeito âmbar daquele associado às propriedades do imã (GILBERT, 1958).

Uma das suposições para diferenciarem os efeitos de atração do âmbar e da magnética era a ausência e regiões polares nos objetos eletrizados. Até então, não havia uma conexão direta entre esses tipos de atração, porque a que era produzida pelo ímã afeta particularmente materiais metálicos, enquanto a atração associada ao âmbar, afeta vários materiais. Mas, a atração associada ao âmbar era bastante inerte se comparada com a da magnética (BERNAL, 1975).

Assim, Gilbert denominou de elétrico os materiais que depois de atritados apresentavam propriedades semelhantes as do âmbar e não elétricos, aqueles que não apresentavam propriedades atrativas, mesmo depois de atritados. Admitiu que a eletrização fosse proveniente de um efluvium liberado pelos corpos, a partir do calor produzido pelo atrito (GILBERT, 1958).

Gilbert admitia a ideia de ação mútua entre dois ímãs ou entre um ímã e um pedaço de ferro. Mas, desconsiderava a ação elétrica mútua entre o âmbar e outro material. Sabe-se atualmente que a ação elétrica assim como a magnética também é mútua e que a força resultante entre os corpos possibilita um deslocamento mútuo em relação a um referencial (ASSIS, 2010).

Durante os séculos XVII e XVIII, vários instrumentos foram construídos visando a detecção da eletrização dos corpos, o armazenamento da eletricidade e ainda para propiciar a eletrização artificialmente os corpos (ROLLER; ROLLER, 1957). Esses instrumentos eram construídos em sintonia com a concepção de eletricidade como fluído.

Um dos instrumentos utilizado para detectar a eletrização dos corpos foi o versório, construído por Gilbert. Consistia de uma agulha disposta horizontalmente, liberada para girar, 
em trono de um pivô vertical (GILBERT, 1958). Mas, evidencias indicam que o instrumento mais antigo usado para detectar a eletrização dos corpos foi o perpendiculum, construído em 1546 por Girolamo Fracastoro (1478-1553), de Verona. Neste, uma linha vertical estava fixada a um suporte e uma porção de âmbar ou prata na extremidade inferior, assemelhando-se a um pêndulo (ASSIS, 2010).

Para a eletrização artificial dos corpos foram construídas algumas máquinas eletrostáticas. Uma das primeiras foi construída em 1672, por Otto Von Guericke (1602-1686). Consistia de uma esfera de enxofre perpassada por um eixo central, acoplado a dois suportes, que possibilitavam o giro do eixo, juntamente com a esfera. Essa seria aperfeiçoada por outros, posteriormente. Os corpos eram eletrizados pelo atrito com o contato da esfera em movimento (ASSIS, 2010).

Entre os séculos XVII e XVIII, desenvolveu-se uma corrente de pensamento que concebia a eletricidade como um fluido que poderia ser armazenado como os demais. Concebendo a eletricidade como um fluído, em 1720, Stephen Gray (1666-1736) constatou que alguns materiais se comportavam semelhantemente ao âmbar. Adotou como elétricos aqueles que possibilitavam a produção da eletricidade (ASSIS, 2010). Adotando a eletricidade como um fluido, em 1745, Pieter von Musschenbroek (1692-1761) construiu um dispositivo para o armazenamento da eletricidade que se tornaria conhecida como a garrafa de Leyden. Consistia de um recipiente de vidro, revestida internamente por finas folhas de prata, parcialmente preenchido com água e com vedação de cortiça, pela qual perpassava um fio metálico. Por este passava o fluido elétrico (BERNAL, 1975).

Por volta de 1740, Charles François du Fay (1698-1739) já havia reproduzindo as experiências com máquinas eletrostáticas e realizado outras, concluindo então que havia dois tipos de fluidos elétricos distintos. Um obtido através da fricção de cristais e o outro, da fricção de resinas. Foram categorizados como eletricidade vítrea e resinosa, respectivamente, os quais eram antagônicos. Os corpos atraíam-se quando eletrizados com fluidos opostos e repeliam-se quando eletrizados com fluido de mesma natureza (BERNAL, 1975).

A ideia da existência de dois tipos de fluidos elétricos seria questionada por Benjamin Franklin (1706-1790), que adotou o modelo de fluido único. O corpo carregado poderia está com falta ou excesso desse fluido, e que a matéria em seu estado natural seria neutra, evidenciando a ideia de conservação da carga (BERNAL, 1975).

Conforme mencionado, durante o século XVII, alguns instrumentos foram construídos com a finalidade de se detectar a atração e repulsão entre corpos eletrizados. Porém, a construção do instrumento de quantificação da força elétrica foi empreendida por Charles Augustin Coulomb (1738-1806), na década de 80 do século XVIII. Coulomb planejou e construiu a balança elétrica de repulsão, cujos resultados possibilitaram quantificar a força elétrica atuando entre dois corpos eletrizados. O detalhamento do instrumento encontra-se na próxima seção. 


\section{A balança elétrica de repulsão}

\section{IV.1 A constituição física da balança elétrica}

Em 1785, Coulomb apresentou a versão final da balança elétrica fundamentada nos princípios da repulsão eletrostática e da torção de fios metálicos. Com essa, empreendeu testes em que a repulsão entre duas esferas eletrizadas, propondo os fundamentos quantitativos para a Lei Fundamental da Eletrostática (Lei de Coulomb). A descrição física da balança elétrica e os procedimentos experimentais realizados com o aparato são descritos na Primeira Memória Sobre a Eletricidade e o Magnetismo, que foi apresentada à Academia de Ciência Francesa. Esta descrição sobre a balança elétrica, assim como as imagens são utilizadas como referencial nesta seção.

A base física da balança elétrica consiste de um cilindro de vidro (ABCD), com diâmetro e altura de 32,48 cm, respectivamente (Fig. 1). A superfície superior deste cilindro é coberta com uma placa de vidro plana, com diâmetro (AC) de $33 \mathrm{~cm}$, aproximadamente. Essa placa possui duas cavidades, com diâmetro de aproximadamente $4,5 \mathrm{~cm}$, cada. Uma destas está centralizada na placa (cavidade $f$ ) e a outra, deslocada à esquerda do centro (cavidade $\mathrm{m}$ ).

$\mathrm{Na}$ cavidade $\mathrm{m}$, encontra-se uma pequena haste $\phi$, confeccionada com goma-laca, com uma esfera de medula t, tecido vegetal esponjoso, fixado na extremidade inferior. Essa haste $\phi$ é fixada por uma pinça disposta horizontalmente sobre

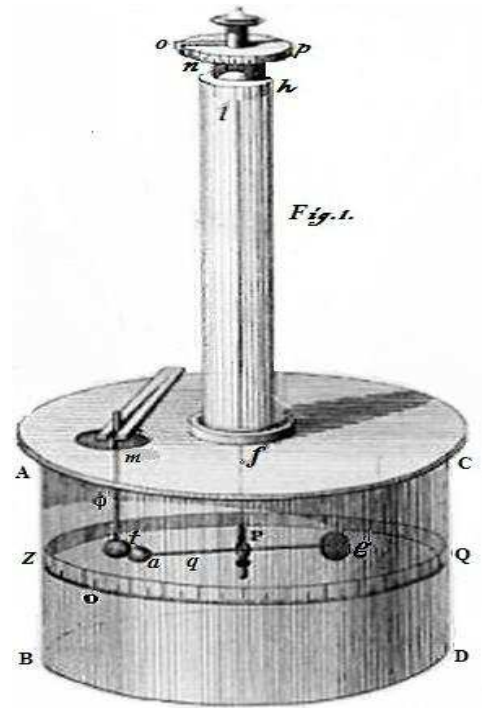

Fig. 1- Balança elétrica. a placa de vidro.

Na cavidade $f$ da placa de vidro, encontra-se um tubo cilíndrico de vidro transparente, com 64,96 cm de altura, sendo $h$ a sua extremidade superior. O cilindro transparente é fixado com uma substância adesiva, usada em materiais elétricos.

$\mathrm{Na}$ extremidade superior do tubo cilíndrico, encontra-se um micrômetro de torção (Fig. 2). Na parte superior do micrômetro, localiza-se a estrutura circular $b$ da peça $\mathrm{n}^{\mathrm{o}} 1$; um ponteiro indicador $i o$, além de uma pinça em forma de bico de pena, disposta verticalmente na extremidade inferior da estrutura circular, cuja abertura pode ser regulada por meio da presilha $q$.

$\mathrm{Na}$ extremidade inferior da pinça, encontra-se um fio de prata delgado. A pinça e o fio são introduzidos na cavidade $\mathrm{G}$ da peça $n^{o} 2$, que se encontra logo abaixo da peça $\mathrm{n}^{\circ} 1$.

A peça $\mathrm{n}^{\circ} 2$ é constituída por um cilindro de cobre $\Phi$, fixado na parte inferior de uma placa circular com diâmetro $a b$, em torno da cavidade central G. No perímetro da circunferência da placa, encon-

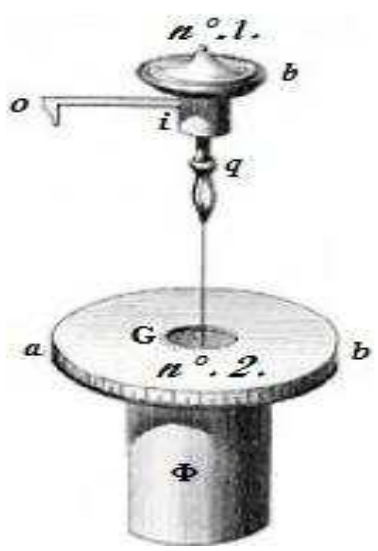

Fig. 2 - Extremidade superior da balança elétrica. tra-se uma escala graduada. $O$ cilindro de cobre $\Phi$ da peça $n^{0} 2$ é encaixado na peça $n^{\circ} 3-$ 


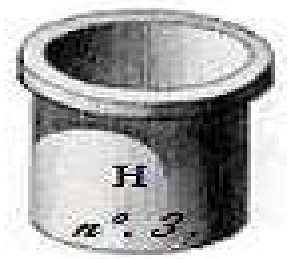

Fig. $3 a$ - Cilindro $\mathrm{H}$.

cilindro H (Fig. 3a). Esse conjunto é acoplado à cavidade superior do cilindro de vidro de altura fh, o qual está centralizado na cobertura do cilindro da base da balança.

Um fio de prata, cujo comprimento é de aproximadamente $75,8 \mathrm{~cm}$, com a extremidade superior 1, fixada na pinça com formato de bico de pena, após atravessar a parte central do cilindro de cobre $\Phi$, o cilindro $\mathrm{H}$ e o tubo de vidro de altura fh, tem uma pinça $o P$ fixada a extremidade inferior, a qual é de cobre ou ferro

(Fig. 3b).

Deve-se considerar que o fio de prata não podia ser muito delgado para não se romper durante os testes, tampouco, muito espesso, para não ter sua flexibilidade à torção atenuada. Além disso, não deveria ser torcido por ângulos com valores muito elevados, para não enrijecer e consequentemente, apresentar imprecisões indesejadas.

A pinça que fixa o fio de prata é ajustada através de um anel $\phi$. Esta possui ainda uma perfuração $\mathrm{C}$, na qual é introduzida horizontalmente uma haste, com 4,06 cm de comprimento. A haste horizontal é produzida a partir de fios de seda ou uma palheta, igualmente envolvidos por cera espanhola. Inserida no cilindro de

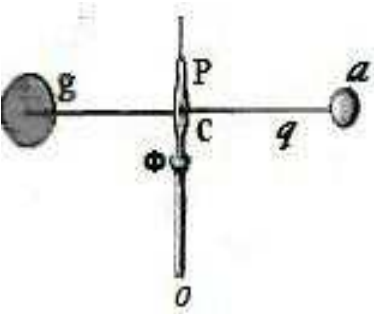

Fig. $3 b-$ Pinça de fixação da extremidade inferior do fio de prata e suspensão da haste horizontal. vidro $\mathrm{ABCD}$, a haste fica disposta horizontalmente, no ponto médio da altura desse cilindro de vidro, como pode ser observado na Fig. 1.

$\mathrm{Na}$ extremidade direita da haste, encontra-se fixada com goma-laca, uma pequena esfera de medula $a$, com diâmetro variando de $0,45 \mathrm{~cm}$ a $0,68 \mathrm{~cm}$, aproximadamente (Fig. $3 \mathrm{~b}$ ). $\mathrm{Na}$ extremidade esquerda da haste, está fixado um pequeno círculo de papel $g$, o qual previamente havia sido imerso em terebentina (líquido então obtido a partir da destilação de resina de coníferas), que, além de contrapeso à bola de medula, amortece as oscilações durante o giro da haste horizontal, no momento da eletrização das esferas $a$ e $t$.

Em torno do cilindro ABCD, na altura da haste, encontra-se fixada uma fita de papel contendo uma escala $\mathrm{ZoQ}$, graduada em $360^{\circ}$.

\section{IV.2 O mecanismo de funcionamento da balança elétrica}

Para operar com a balança elétrica, Coulomb introduzia a haste vertical $\phi$ fixada à esfera $t$ na cavidade $m$ da placa de vidro que recobre o cilindro $\mathrm{ABCD}$. A posição da cavidade $\mathrm{m}$ foi ajustada de modo que possibilitasse posicionar a esfera $\mathrm{t}$ coincidindo com a origem $O$ da escala de papel ZOQ, localizada em torno do ponto médio da altura do cilindro de vidro da base.

Coulomb também ajustava o ponteiro io do micrômetro sobre a origem da escala situada na estrutura circular de diâmetro $a b$ da peça $\mathrm{n}^{\circ} 2$ (Fig. 2). Em seguida, girava o micrô- 
metro em torno do cilindro de vidro $f$ h (Fig. 1), até o momento em que a haste horizontal, suspensa pelo fio de prata, se posicionasse também na origem o da escala do cilindro. Assim a esfera $a$ ficava em contato com a esfera $t$ e coincidindo com a primeira divisão da escala ZoQ.

Antes de submeter balança elétrica aos testes experimentais, Coulomb tomou algumas precauções. Dentre estas, a utilização de um fio de prata delgado, muito sensível à torção. Assim, para distintos valores de ângulos entre as esferas a e t, Coulomb constatou as forças de torções correspondentes. Coulomb era conhecedor da sensibilidade de distintos materiais à torção, tendo sido engenheiro da Armada francesa e dentre suas atribuições, era o responsável pela confecção e manutenção de equipamentos náuticos.

Outra precaução consistia na minimização dos efeitos de perturbação do ar durante os testes experimentais, além de posicionar a haste horizontal, sem produzir torção no fio de prata. Segundo Coulomb, não seria possível ajustar com precisão tal posição, mas, apenas fazer estimativas aproximadas de $2^{\circ}$ a $3^{\circ}$. Assim realizou um teste inicial para obter um padrão de ajuste para os testes subsequentes. Depois de eletrizar as esferas a e t, devia-se torcer o fio de suspensão de $30^{\circ}$ a $40^{\circ}$, através do micrômetro, a fim de aproximá-las a uma distância tal que produza uma força de torção suficientemente considerável para que os $2^{\circ}$ ou $3^{\circ}$ de incerteza na primeira posição da agulha e não produza nos resultados um erro considerável.

Inicialmente, as esferas $a$ e $t$, eletricamente neutras, encontravam-se em contato e não manifestavam nenhum efeito elétrico. Com o propósito de eletrizar as esferas $t$ e $a$, Coulomb introduzia pela cavidade $m$, uma Fig. 4 - Esfera condutora fixada à palheta. pequena esfera condutora e eletrizada e a colocava em contato com a esfera $t$. A esfera eletrizada encontrava-se fixada a uma pequena palheta de cera espanhola, que a tornava eletricamente isolada (Fig. 4).

Após o contato da esfera eletrizada com a esfera t, removia-se aquela, que ocasionava a eletrização das esferas $t$ e a com eletricidade da mesma natureza, haja vista que estavam inicialmente em contato no interior do cilindro ABCD. Devido à ação repulsiva da força elétrica entre a esfera t, fixa, e a esfera a, móvel, ocorre a rotação da haste $a g$. Esse afastamento entre o centro das esferas a e t era reconhecido por meio da posição ocupada pelo centro da esfera $a$, em relação à graduação da escala ZoQ.

Para aferir no micrômetro o afastamento consequente da repulsão elétrica entre as esferas $a$ e $t$, Coulomb girava o ponteiro do micrômetro no sentido pno (sentido horário), consequentemente torcendo o fio de suspensão $l \mathrm{P}$, produzindo neste uma torção proporcional ao ângulo que tendia a aproximar a esfera a da esfera t. Essa força de torção equilibrava-se com a força elétrica para cada distância entre as esferas. A partir da comparação das distâncias entre as esferas relacionadas às torções no fio, determinava da repulsão elétrica em função da distância.

Deve-se salientar que, Coulomb antes de construir a balança elétrica de repulsão, já havia construído uma balança de torção e investigado a resistência de vários tipos de fios à 
torção e constatado que, um fio de prata mais delgado que aquele utilizado no experimento, para propiciar uma melhor precisão na medida da torção, deveria ser suspenso por um peso correspondente a cerca da metade do que ele pode suportar sem romper-se. Ainda devia-se considerar que este fio, nunca deveria ser torcido para além de $300^{\circ}$, haja vista que, partir deste valor limite, o fio enrijecia e perdia a sensibilidade à torção.

Para argumentar sobre a validade da lei da repulsão elétrica entre os corpos carregados, Coulomb discorreu sobre três testes realizados com a balança elétrica de repulsão. No primeiro teste, a esfera condutora móvel (Fig. 4) eletrizava as duas esferas condutoras em contato ( $\mathrm{t}$ e a) localizadas no interior do cilindro de vidro. $\mathrm{O}$ ponteiro do micrômetro estava apontando para $0^{\circ}$, na escala do micrômetro. Enquanto a esferas a, fixada na haste horizontal, se afasta da esfera $t$ por $36^{\circ}$, registrado na escala em torno do cilindro ABCD. Esta medida corresponde a uma força de 0,0156 dinas. Ou seja, neste caso específico, a separação entre as esferas corresponde à própria torção no fio.

No segundo teste realizado por Coulomb com a balança elétrica, através do ponteiro do micrômetro, o fio de suspensão fixado à haste horizontal era torcido para $126^{\circ}$ no sentido horário. Aproximando a esfera a da esfera t para metade da distância anterior, ou seja, $18^{\circ}$. Neste caso, a torção total tem valor quadruplicado em relação ao teste anterior.

No terceiro ensaio, Coulomb girou o ponteiro do micrômetro para um ângulo de $567^{\circ}$, também em sentido horário, a partir dos $126^{\circ}$ já registrados, causando uma torção no fio, ao mesmo tempo em que a esfera móvel se aproximou da fixa por uma distância angular de não mais que $8,30^{\circ}$. Consequentemente, a torção total corresponde à soma da torção no micrômetro com a distância angular entre as esferas, totalizando $576^{\circ}$. Quadruplicada em relação ao teste anterior, requerendo apenas metade de um grau a mais para que a distância entre as duas esferas na terceira experiência, pudesse ser reduzida à metade da distância das mesmas na experiência anterior.

Ainda a fim de minimizar os erros nas medidas, Coulomb levou em conta que a eletricidade das duas esferas diminuía sensivelmente durante o intervalo de tempo da realização do experimento. Quando as esferas a e t estavam separadas por $30^{\circ}$, enquanto o ponteiro do micrômetro é ajustado em $50^{\circ}$, elas se aproximam cerca de um grau em três minutos. Mas para realizar os três testes, citados anteriormente, foram utilizados apenas dois minutos. Logo, pode-se nestas experiências desprezar o erro decorrente da perda de eletricidade. Coulomb constatou ainda que quando o ar estava úmido a eletricidade se dispersava rapidamente, assim, deviam-se fazer correções para uma maior precisão nas medidas.

De acordo com os resultados dos três testes anteriores, podemos inferir que, quando a distância entre as esferas tende a ser reduzida pela metade, a força de torção tende a ser quadruplicada, ou seja, para diminuir a separação das esferas pela metade, então teremos que torcer o fio quatro vezes tanto quanto esta torção inicial. Vale ressaltar ainda que a torção total no fio poderia ser tomada como correspondente a força de repulsão. 
Os resultados, a partir dos três testes, evidenciam que a ação repulsiva entre as duas esferas eletrizadas é uma ralação do tipo inverso do quadrado da distância.

\section{Percurso metodológico}

\section{V.1 O perfil da pesquisa}

A partir do objetivo estabelecido para a presente investigação, nos pautaremos pelas questões de pesquisa, a seguir:

1) Qual o grau de iconicidade das representações imagéticas da balança elétrica nos livros didáticos de física, adotando como referência as imagens da Primeira Memória de Coulomb?

2) Quais as etiquetas verbais adotadas pelos autores em relação as imagens da balança elétrica e como são mobilizadas pelo texto relacionado às imagens?

3) Ocorre correspondência entre a abordagem textual e a representação imagética da balança elétrica de Coulomb nas abordagens dos livros didáticos?

Pelo teor das questões de pesquisa, mobilizaremos três categorias da taxonomia de Perales e Jiménez (2002), abordadas anteriormente em seção específica. São elas: o grau de iconicidade da representação imagética; as etiquetas verbais e a relação texto-imagem.

\section{V.2 Os livros didáticos}

Para esta pesquisa, selecionamos texto e imagens sobre a balança elétrica em dez livros didáticos de Física destinados no nível médio da educação básica brasileira, aprovados pelo Programa Nacional de Avaliação do Livro Didático para o Ensino Médio (PNELEM), editados entre os anos de 2010 e 2012.

As referências dos livros analisados encontram-se no Quadro I, respectivamente nomeados como livros $\mathrm{L}_{1}, \mathrm{~L}_{2}, \mathrm{~L}_{3}, \mathrm{~L}_{4}, \mathrm{~L}_{5}, \mathrm{~L}_{6}, \mathrm{~L}_{7}, \mathrm{~L}_{8}, \mathrm{~L}_{9}$ e $\mathrm{L}_{10}$.

Quadro I - Referências dos livros didáticos.

\begin{tabular}{|c|c|}
\hline Autores & Livros Analisados \\
\hline BRAZ, D.; SANTOS, R. T. & Física. v. 3, São Paulo, SP: Escala educacional, 2010. $\left(\mathrm{L}_{1}\right)$ \\
\hline $\begin{array}{l}\text { YAMAMOTO, K.; FUKE, L. } \\
\text { P. }\end{array}$ & $\begin{array}{l}\text { Física Para o Ensino Médio, v.3, } 2 \text { ed. São Paulo, SP: Editora Saraiva } 2011 . \\
\left(\mathrm{L}_{2}\right)\end{array}$ \\
\hline PIETROCOLA, M. et al. & $\begin{array}{l}\text { Física em contextos pessoal, social e histórico: eletricidade e magnetismo, } \\
\text { ondas eletromagnéticas, radiação e matéria, v. 3. São Paulo, SP: Editora } \\
\text { FTD. 2010. }\left(L_{3}\right)\end{array}$ \\
\hline $\begin{array}{l}\text { RAMALHO Jr, } \quad \text { F., } \\
\text { FE;RRARO, N. G.; SOARES, } \\
\text { P. A. T. }\end{array}$ & $\begin{array}{l}\text { Os Fundamentos da Física. v. 3. São Paulo: Editora Moderna, } 10 \text { ed. } 2010 . \\
\left(L_{4}\right)\end{array}$ \\
\hline $\begin{array}{l}\text { TORRES, C. M; FERRARO, } \\
\text { N. G.; SOARES, P. A. T. }\end{array}$ & $\begin{array}{l}\text { Física. Ciência e Tecnologia, v. 3. Eletromagnetismo e Física Moderna, } 2^{\mathrm{a}} \\
\text { ed. São Paulo, SP: Editora Moderna, 2010. }\left(\mathrm{L}_{5}\right)\end{array}$ \\
\hline GASPAR, A. & $\begin{array}{l}\text { Compreendendo a Física. Eletromagnetismo e Física Moderna. Vol.3. São } \\
\text { Paulo: Editora Ática, 2011. }\left(\mathrm{L}_{6}\right)\end{array}$ \\
\hline OSCANO, C. & $\begin{array}{l}\text { Física e Realidade: Ensino Médio Física, Vol.3 São Paulo: editora Scipione, } \\
\text { 2012. }\left(\mathrm{L}_{7}\right)\end{array}$ \\
\hline
\end{tabular}




\begin{tabular}{|l|l|}
\hline $\begin{array}{l}\text { MÁXIMO, A.; ALVAREGA, } \\
\text { B. }\end{array}$ & Curso de Física, Vol. 3, São Paulo: Editora Scipione, 2012. (L L $\left._{8}\right)$ \\
\hline $\begin{array}{l}\text { SANT'ANNA, B.; MARTINI, } \\
\text { G.; REIS, H. C.; SPINELLI, H. }\end{array}$ & $\begin{array}{l}\text { Conexões com a Física, v. 3, Eletricidade. Física do século XXI, São Paulo: } \\
\left.\text { SP, Ed Moderna, 1 ed, 2011. (L }{ }_{9}\right)\end{array}$ \\
\hline $\begin{array}{l}\text { DA SILVA, C. X.; BARRETO, } \\
\text { B. }\end{array}$ & $\begin{array}{l}\text { Física. Aula por Aula. V. 3, Eletromagnetismo, Ondulatória, Física Moder- } \\
\text { na, 1. Ed., São Paulo, SP: 2010. }\left(\mathrm{L}_{10}\right)\end{array}$ \\
\hline
\end{tabular}

\section{V.3 A construção e a mobilização dos referenciais teóricos}

Para contemplar os objetivos da pesquisa, construímos duas vertentes teóricas. Uma relacionada à construção da balança elétrica de Coulomb, contextualizada ao desenvolvimento da eletricidade e do magnetismo, nos séculos XVII e XVIII. Consultamos originais, especificamente A Primeira Memória Sobre a Eletricidade e o Magnetismo de Coulomb (Memórias), o The Magnet de Gilbert, além de fontes secundárias que incorporam confiabilidade teórica. A outra vertente contemplou teorizações sobre as linguagens verbal e imagética, especificamente relacionadas à educação científica.

Selecionamos as imagens dos livros didáticos, juntamente com as respectivas etiquetas verbais, além dos textos que se referiam às imagens. Estes constituem as unidades de análise referente à linguagem verbal.

Trata-se de uma pesquisa qualitativa porque foca os processos e não apenas os resultados, ou seja, considera-se o texto, a imagem e a articulação entre eles (BOGDAN: BIKLEN, 1994).

A partir das questões de pesquisa, a abordagem de cada livro didático foi analisada individualmente, seguindo a ordem de nomeação, especificada no Quadro I.

\section{A balança elétrica nas abordagens dos livros didáticos}

Analisamos nesta seção as abordagens dos livros didáticos sobre a balança elétrica de repulsão, a partir das questões de pesquisas.

\section{VI.1 Análise das abordagens do livro L1}

No livro $\mathrm{L}_{1}$ há uma representação da balança elétrica (Imagem A) que, quanto ao grau de iconicidade, classificamos como desenho figurativo. Apesar de se tratar de uma representação que tenta se aproximar do objeto real, alguns constituintes do aparato foram suplantados, como o ponteiro do micrômetro na parte superior do tubo central, a pinça que sustenta a haste vertical introduzida no orifício da cobertura da base do cilindro. Além disso, não representam a esfera fixada em uma haste isolante (Fig. 4), utilizada para eletrizar as esferas no

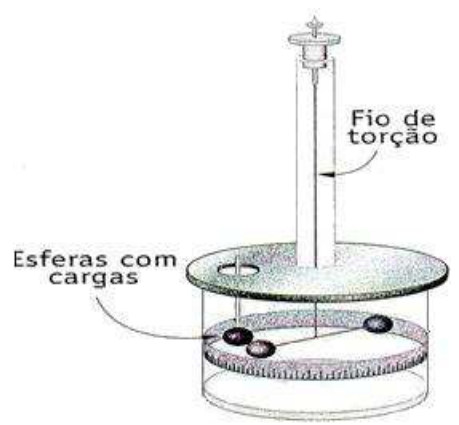

Imagem A - Representação imagética da balança elétrica no livro $L_{1}$. interior do cilindro. 
Ainda na imagem A, na extremidade direita da haste horizontal, localizada no interior do cilindro, encontra-se fixada uma esfera, ao invés de um círculo de papel, que, na balança referência, funciona como contrapeso. Ou seja, trata-se de uma imagem que dificulta uma explicação sobre o funcionamento do aparato.

Duas etiquetas verbais nominativas estão associadas à imagem A. Uma se refere ao fio de suspensão da haste, substituindo a qualificação do material pelo princípio físico que atua durante o funcionamento do aparato. A outra nomeia as esferas com uma das suas propriedades, apesar do conceito de carga ainda não ter sido elaborado na época da construção do aparato.

Sobre o aparato experimental, os autores do livro $\mathrm{L}_{1}$ assinalam:

Em 1785, por meio de experiências com uma balança de torção, o físico francês Charles Augustin de Coulomb verificou que a intensidade da força eletrostática entre duas cargas elétricas puntiformes é diretamente proporcional ao produto dos módulos das cargas e inversamente proporcional ao quadrado da distância que as separa. Essa lei ficou conhecida como Lei de Coulomb. [...] para estabelecer a lei, Coulomb usou duas pequenas esferas eletrizadas e fixadas em uma haste. A haste era sustentada por um fio que podia girar. Uma terceira esfera eletrizada era aproximada de uma das esferas, causando a torção no fio (p. 22-23).

Inicialmente os autores nomeiam o aparato como balança de torço. No entanto, Coulomb utilizou uma balança de torção antes da construção da balança elétrica, com a finalidade de mensurar as torções suportadas por fios de distintas naturezas. Prosseguindo, mencionam alguns supostos resultados obtidos a partir do manuseio do aparato, os quais teriam possibilitado a construção de uma lei para as forças eletrostáticas.

Refere-se a uma terceira esfera, não representada, que eletrizaria as outras duas no interior do cilindro. Mas, não mencionam os processos de eletrização, o material constituinte das esferas, tampouco aos ajustes necessários para aferição da repulsão. Ou seja, o texto não prioriza uma exploração do aparato no sentido de evidencia o seu funcionamento.

Na unidade de análise do livro $L_{1}$, não se reportam às etiquetas verbais, as quais poderiam contribuir para o entendimento do aparato experimental. Classificamos a relação texto-imagem como conotativa, pela breve mobilização dos elementos da imagem.

\section{VI.2 Análise das abordagens do livro $L_{2}$}

No livro $\mathrm{L}_{2}$ encontram-se três imagens relacionadas à balança elétrica (Imagens $\mathrm{B}_{1}, \mathrm{~B}_{2}$ e $\mathrm{B}_{3}$ ). No tocante ao grau de iconicidade, classificamos a representação $\mathrm{B}_{1}$ como desenho figurativo. Porém, foram suplantados a pinça de sustentação da haste vertical que contém uma esfera (esfera

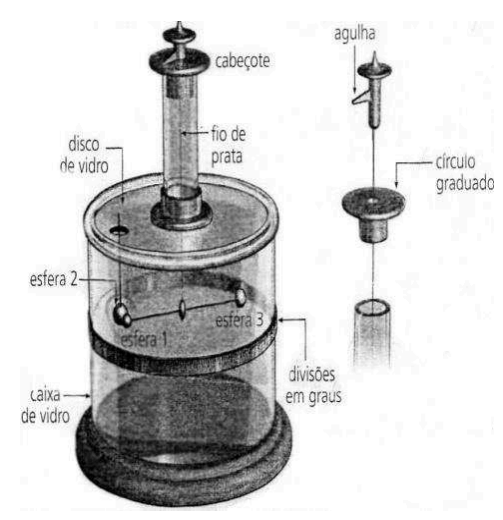

Imagem $B_{1}-$ Representação imagética da balança elétrica no do livro $L_{2}$. 
2) introduzida na cavidade esquerda da cobertura do cilindro da base e a haste isolante com uma esfera na extremidade (Imagem 4), a qual se presta para eletrizar a esfera 2. O círculo de papel está representado por uma esfera (esfera 3).

No experimento original, a dimensão da altura do cilindro central é aproximadamente o dobro da altura do cilindro da base do aparato. Nesse, a altura do cilindro da base é superior a do cilindro central, o que comprometeria a precisão do seu funcionamento.

$\mathrm{Na}$ imagem $\mathrm{B}_{1}$, alguns constituintes do aparato encontram-se representados separadamente, como a agulha e a escala do micrômetro.

Relacionadas à imagem $\mathrm{B}_{1}$, encontram-se dez etiquetas verbais classificadas como nominativas. Apesar de aclararem os constituintes da balança, não há texto relacionado.

A imagem $B_{2}$ representa uma vista da perspectiva superior das três esferas no interior do cilindro da base, em situação de suposto funcionamento da balança elétrica. Quanto ao grau de iconicidade, classificamos como desenho esquemático mais signos.

A esfera 1 está representada com dimensões maiores que a esfera 2 e o círculo de papel é substituído pela es-

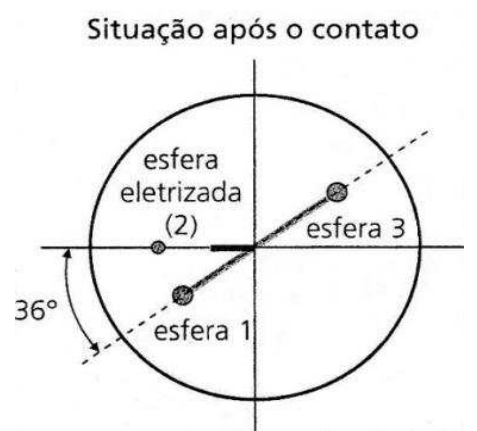

Imagem $B_{2}-$ Vista superior das três esferas no interior do cilindro. fera 3, incompatíveis com a referência.

Associadas a imagem $\mathrm{B}_{2}$ encontram-se quatro etiquetas verbais. Três delas referemse às esferas localizadas no interior da balança e classificamos como nominativas. Outra etiqueta refere-se ao afastamento da esfera 1, supostamente após a eletrização da esfera 2. Assim, classificamos esta etiqueta verbal como relacional, porque descreve relações entre elementos da imagem.

Sobre a imagem $\mathrm{B}_{2}$, os autores assinalam:

Além disso, uma barra isolante horizontal, com duas esferas metálicas (1 e 3 ) presas nas extremidades, é suspensa por um fino fio de prata preso ao cabeçote. A barra isolante pode girar livremente diante de uma graduação de 0 a $360^{\circ}$, inscrita numa fita de papel colada na caixa de vidro (p. 34).

Mencionam alguns componentes da balança elétrica e suas propriedades, como o fio de suspensão de prata, a barra horizontal isolante, bem como as esferas metálicas. No entanto, não se referem à relação das propriedades destes componentes com o funcionamento do aparato. Por exemplo, não mencionam que o fio de suspensão deve ser delgado no sentido de ser sensível a torção, que deve ser de prata ou outro material resistente no sentido de não se romper com o peso da estrutura suspensa. Também não se referem ao processo de eletrização das esferas, a qual levará a barra horizontal a girar. 
A afirmativa de que a barra isolante pode girar livremente de $0^{\circ}$ a $360^{\circ}$ é incompatível para a representação anterior, pois a existência da esfera 3 na haste inibe a sua rotação para os ângulos citados, devido a esfera 2 está fixa no mesmo plano horizontal. Nesta perspectiva a rotação máxima permitida para a haste seria de aproximadamente $180^{\circ}$.

A desarticulação texto-imagem, associada a omissões de componente da imagem $\mathrm{B}_{2}$ poderá dificultar a compreensão pelo leitor ou propiciar interpretações errôneas da mesma. Ou seja, apesar dos detalhes da imagem, o texto não a explora coerentemente. Classificamos a coerência texto-imagem na abordagem sobre a imagem 2, como uma relação denotativa, devido menções aos elementos da ilustração. No entanto, as ausências de alguns elementos no aparato experimental, bem como de detalhes textuais, dificultam uma articulação da abordagem textual com a imagética.

A terceira representação imagética do livro $\mathrm{L}_{2}$, imagem $B_{3}$, a qual se refere a um suposto teste realizado com a

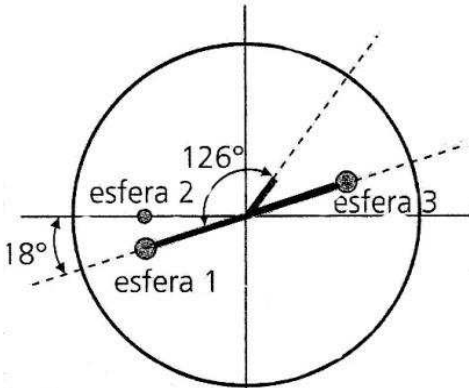

Imagem $B_{3}-$ Vista superior de uma representação da balança elétrica no livro $L_{2}$. balança elétrica. Quanto ao grau de iconicidade, classificamos como desenho esquemático mais signos. Nesta, as esferas 2 e 3 apresentam dimensões distintas.

Semelhantemente as imagens $\mathrm{B}_{1}$ e $\mathrm{B}_{2}$, em $\mathrm{B}_{3}$ reproduzem o equívoco de substituírem a representação do círculo de papel da extremidade direita da haste horizontal como uma esfera (esfera 3).

Associadas a imagem $B_{3}$ encontram-se cinco etiquetas verbais. Três nomeiam as esferas, logo, classificamos como nominativas. As outras se referem ao deslocamento angular após uma suposta repulsão entre as esferas 2 e 1 . Classificamos estas etiquetas verbais como relacionais.

Ainda no livro $\mathrm{L}_{2}$, outra incompatibilidade quanto à coerência entre texto e imagem, refere-se ao segundo teste realizado por Coulomb em suas experiências com a balança. Sobre esta e referindo-se a imagem $\mathrm{B}_{3}$, assinalam:

Girando o cabeçote em $126^{\circ}$ no sentido horário, diminui o deslocamento angular sofrido pela barra isolante para aproximadamente metade $\left(18^{\circ}\right)$. Conclui-se, então, que para diminuir o ângulo para metade do valor inicial (diminuindo a distância, portanto), a força de torção no fio teve que ser aumentada 4 vezes: $126^{\circ}+18^{\circ}=144^{\circ}$ $=4 \times 36^{\circ}$ (p. 34).

Com relação à imagem correspondente a esta descrição textual (Fig. $\mathrm{B}_{3}$ ), observa-se que o ângulo formado entre a barra isolante e o ponteiro do micrômetro que deveria ser $144^{\circ}$, correspondendo à soma da torção angular do micrômetro $\left(126^{\circ}\right)$ com o deslocamento angular da barra isolante $\left(18^{\circ}\right)$. É equivocadamente explicitado na imagem como sendo $126^{\circ}$, contradizendo a informação textual e, consequentemente dificultando a interpretação quantitativa dos resultados que corroboraram com as interpretações de Coulomb. Essa desarticulação tex- 
to-imagem poderá dificultar a compreensão do funcionamento do aparato. Apesar do texto reportar-se à imagem, pelo teor deste, classificamos a relação como conotativa.

\section{VI.3 Análise das abordagens do livro L3}

No livro $\mathrm{L}_{3}$ encontram-se quatro imagens relacionadas à balança elétrica (Imagens $\mathrm{C}_{1}, \mathrm{C}_{2}, \mathrm{C}_{3}$ e $\mathrm{C}_{4}$ ). A primeira (Imagem $\mathrm{C}_{1}$ ) é uma reprodução da imagem existente nas Memórias de Coulomb. Logo, em relação ao grau de iconicidade, trata-se de uma fotografia. Nesta encontram-se as etiquetas verbais nominativas existentes na imagem referência.

Como alguns elementos do aparato encontram-se representados separadamente, possibilitaria uma exposição detalhada dos constituintes desses.

Após a exposição da imagem $\mathrm{C}_{1}$, os autores assinalam:

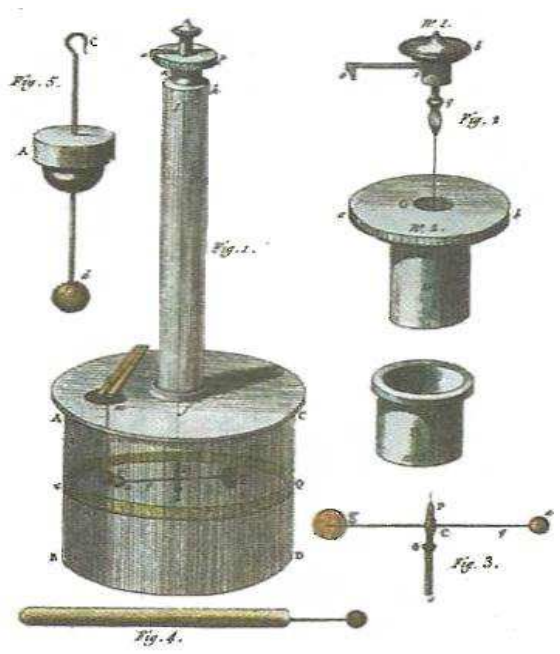

Imagem $C_{1}-$ Representação imagética da balança elétrica no livro $L_{3}$.

Em 1785, o físico francês Charles Coulomb utilizou uma balança de torção para medir a intensidade da atração ou repulsão entre corpos eletrizados (p. 36).

Conforme mencionado, Coulomb havia utilizado uma balança de torção com outros propósitos. Além disso, a balança elétrica representada foi utilizada para aferir a repulsão entre as esferas eletrizadas e não a atração.

O excerto anterior não faz nenhuma menção ao princípio de funcionamento do aparato experimental, tampouco a sua constituição e mecanismos de funcionamento. Refere-se a teorizações elaboradas a partir das experimentações realizadas com o aparato. Logo, classificamos a relação texto-imagem como sendo uma abordagem conotativa.

A segunda imagem do livro $\mathrm{L}_{3}$ referente à balança elétrica (Imagem $\mathrm{C}_{2}$ ) classificamos como desenho figurativo. Po-

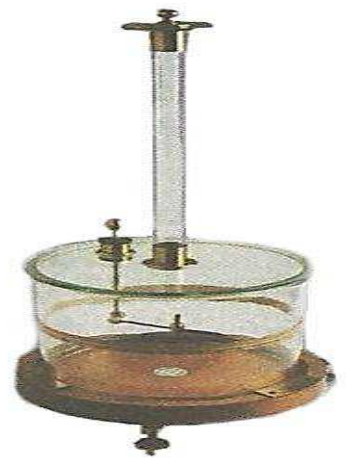

Imagem C2 - Representação imagética da balança elétrica no livro L3. rém, em relação à imagem original, alguns componentes foram suplantados, como a escala e o ponteiro do micrômetro e a pinça de sustentação da haste vertical introduzida no interior do cilindro da base. Além disso, não há representação da graduação da escala da base do cilindro.

A esfera fixa a uma haste isolante, a qual irá eletriza por contato uma esfera localizada na base da balança, em $\mathrm{C}_{2}$ mostra-se substituída por uma esfera localizada na cobertura 
do cilindro da base da balança. A imagem $\mathrm{C}_{2}$ não apresenta etiquetas verbais, nem texto associado.

Prosseguindo, no livro $\mathrm{L}_{3}$ encontram-se duas imagens (Imagens $\mathrm{C}_{3}$ e $\mathrm{C}_{4}$ ). No tocante ao grau de iconicidade, classificamos ambas como desenho esquemático mais signos. Nessas imagens, a haste horizontal encontra-se com espessura semelhante ao fio de sustentação, o que se incompatibiliza com a precisão das medidas, haja vista a diminuição da sua sensibilidade em relação à força de repulsão
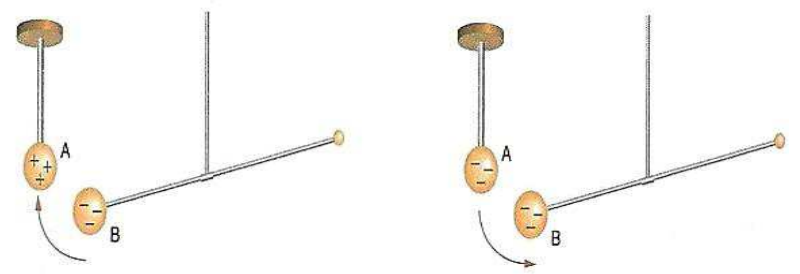

Imagens $C_{3}$ e $C_{4}$-Representações imagéticas de componentes da balança elétrica durante os testes experimentais realizados por Coulomb, localizadas no livro $L_{3}$. proveniente da interação entre as esferas A e B, após a eletrização. Apesar de ser um esquema, poderá induzir o leitor a erros.

Em ambas as representações, na extremidade direita da haste encontra-se uma pequena esfera ao invés de um círculo, conforme a representação original.

Associadas a cada uma das representações imagéticas $C_{3}$ e $C_{4}$ encontram-se as etiquetas verbais nominativas A e B, referentes a duas esferas distintas. Além dessas, encontram-se etiquetas verbais indicando a natureza positiva e negativa da eletrização das esferas A e B, bem como as representadas por setas indicando atração ou repulsão entre essas, a partir da natureza das eletrizações. Logo, classificadas essas quatro etiquetas verbais como relacionais.

Referindo-se às imagens $\mathrm{C}_{3}$ e $\mathrm{C}_{4}$, porém, sem relacioná-las as imagens $\mathrm{C}_{1}$ e $\mathrm{C}_{2}$, assinalam:

Aproximando as esferas carregadas com sinais e quantidades de carga iguais e diferentes, Coulomb mediu a deflexão causada pela torção do fio. Após realizar uma série de cuidadosos testes e analisar detalhadamente os resultados, concluiu que as forças de atração e repulsão entre os corpos eletrizados eram diretamente proporcionais ao produto dos módulos das cargas [...] Observou também que a força elétrica tinha sua intensidade variada de acordo com o inverso do quadrado da distância entre elas [...] (p. 36).

$\mathrm{Na}$ imagem, evidenciam-se as esferas com quantidades iguais de cargas iguais, haja vista tratar-se de uma eletrização por indução. Mas, não é possível identificar através da imagem como a deflexão pode ser aferida, haja vista que o micrômetro, assim como outros constituintes não são apresentados. Também não é possível relacionar como os procedimentos seguidos por Coulomb no tocante a aferição das forças entre as esferas, nem mesmo como foi generalizado para outras situações. 
Apesar das quatro etiquetas verbais associadas às imagens $C_{3}$ e $C_{4}$ não são mobilizadas pelo texto para uma explicação sobre o aparato. Interpretamos que a relação texto-imagem incorpora uma relação denotativa.

\title{
VI.4 Análise das abordagens do livro $L_{4}$
}

No livro $\mathrm{L}_{4}$ encontra-se uma imagem relacionada à balança elétrica (Imagem D) que, quanto ao grau de iconicidade, classificamos como desenho figurativo. Nesta, a maior parte dos componentes do aparato encontra-se representado, tais como o ponteiro e a escala do micrômetro, a escala da base, a pinça de sustentação da haste vertical e outros.

Igualmente as representações anteriores, na imagem D, uma esfera substitui o círculo de papel localizado na extremidade direita da haste horizontal, no interior do cilindro da base. Encontra-se ausente a representação da esfera fixada em uma haste isolante, com a qual se eletriza a esfera fixada na haste vertical (Fig. 4), situada no interior do cilindro (esfera $b$ ). Compatibilizando-se com o aparato original, a haste horizontal é bem mais espessa que o fio vertical pelo qual é sustentada. Assim, não compromete a sensibilidade à torção das forças de repulsão ente as esferas $a$ e $b$.

Associadas à imagem $\mathrm{D}$, existem duas etiquetas verbais nominativas as quais se encontram mencionadas no texto relacionando-o a imagem. Assinalam:

\begin{abstract}
Uma barra isolante terminada em duas pequenas esferas metálicas é suspensa por um delgado fio de prata. Outra barra isolante, provida no seu extremo de uma pequena esfera metálica b carregada, é introduzida pelo orifício superior. As esferas a e b são colocadas em contata e a eletriza-se com carga de mesmo sinal que b. As esferas repelem-se, o que provoca a torça no fio de suspensão. A intensidade da força elétrica é proporcional ao ângulo de torção. Medindo o ângulo de torção para diferentes distâncias entre a e b, Coulomb estabeleceu a lei do inverso do quadrado da distância. Mantendo a distância e mudando as cargas convenientemente, ele estabeleceu que a intensidade da força elétrica é diretamente proporcional ao produto das cargas (p. 15).
\end{abstract}

Igualmente à representação imagética, o texto se refere às esferas nas extremidades da haste horizontal isolante, localizada no interior do cilindro da base. Porém, a esfera não é metálica, mas vegetal. Mencionam o fio de prata delgado que sustenta a haste horizontal, porém, não discute a razão dessa espessura. Também reportam-se a uma esfera metálica a ser introduzida no orifício superior da cobertura do cilindro da base. Mas, a mencionada esfera não está representada. Prosseguindo, reportam-se a repulsão entre as esferas $a$ e $b$, após o processo de eletrização e a consequente torção provocada na haste, a qual teria possibilitado a determinação da

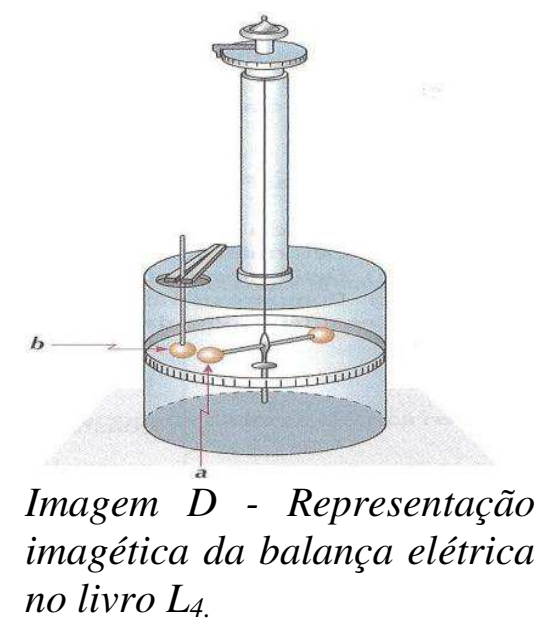


força de repulsão elétrica entre as esferas.

Pela ausência de etiquetas verbais, avaliamos que dificulta ao leitor proceder com uma correlação entre o texto e imagem, notadamente em relação ao funcionamento do aparato, como por exemplo, a medida do denominado ângulo de torção. Nesta, a escala localizada no cilindro da base, através da qual se identifica intensidade da repulsão entre as esferas, não é mobilizada. Interpretamos que não subsidiam o leitor na localizar o ângulo de torção para os diferentes distanciamentos angulares entre as esferas a e b.

Pelas considerações anteriores, classificamos a relação texto-imagem como incorporando uma tendência denotativa, haja vista as referências à imagem. No entanto, essa relação ainda é bastante superficial.

\section{VI.5 Análise das abordagens do livro $L_{5}$}

O livro $\mathrm{L}_{5}$ traz uma imagem da balança elétrica (Imagem E), que, quanto ao grau de iconicidade classificamos como desenho figurativo.

$\mathrm{Na}$ extremidade direita da haste horizontal no interior do cilindro da base, encontra-se representada uma esfera, ao invés de um plano em forma de círculo. A relação entre a altura do tubo central e a do cilindro da base do aparato não se compatibiliza com a imagem referência. Não está representada a esfera fixada em uma haste isolante (Fig. 4), a qual eletrizará a esfera $\mathrm{A}$, iniciando o funcionamento do aparato.

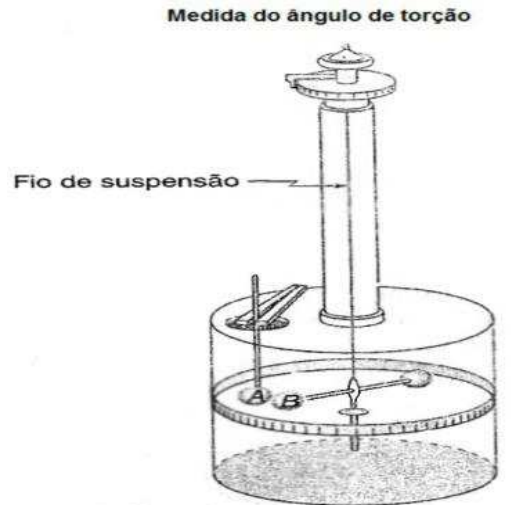

Imagem E - Representação imagética da balança elétrica no livro $L_{5}$.

Associadas à imagem E, encontram-se quatro etiquetas verbais que de acordo com o referencial são nominativas. Referem-se à escala do micrômetro, na parte superior da imagem, ao fio de suspensão da haste horizontal e a duas esferas (A e B), no interior do cilindro da base. Vários componentes do aparato não possuem etiquetas associadas como as escalas da base e a associada ao micrômetro, o ponteiro do micrômetro e outros.

$\mathrm{Na}$ abordagem textual sobre a balança elétrica, os autores do livro $\mathrm{L}_{5}$, assinalam:

Realizando experiência com um dispositivo chamado balança de torção, Coulomb conseguiu medir a intensidade de forças de atração e de repulsão entre duas pequenas esferas carregadas eletricamente.

Analisando os resultados obtidos, Coulomb estabeleceu a lei que leva seu nome. Ele verificou que as forças elétricas apresentavam intensidades diretamente proporcionais aos módulos das cargas dos corpos que estavam interagindo e inversamente proporcionais ao quadrado das distâncias entre seus centros (p. 25).

Conforme já mencionado, a balança de torção havia sido utilizada por Coulomb com outros propósitos. Com a balança elétrica aferia apenas a repulsão entre as entre as esferas 
eletrizadas e não a atração. Além disso, o texto foca em afirmações conclusivas em detrimentos dos processos teóricos e experimentais.

Notamos ainda que, apesar dos detalhes da configuração do aparato, as etiquetas verbais associadas não são mobilizadas, no sentido de auxiliar o leitor na compreensão da relação entre os dados obtidos a partir do aparato ou mesmo o funcionamento deste. Interpretamos que, na abordagem do livro $\mathrm{L}_{5}$, a relação texto-imagem é conotativa.

\section{VI.6 Análise das abordagens do livro $\mathrm{L}_{6}$}

No livro $\mathrm{L}_{6}$, há uma representação da balança elétrica de Coulomb, semelhante à referência (Imagem F), inclusive com as etiquetas verbais. Logo, quanto ao grau de iconicidade, classificamos como fotografia ${ }^{3}$, sendo as etiquetas verbais nominativas.

$\mathrm{Na}$ abordagem textual do livro $\mathrm{L}_{6}$ sobre o aparato, o autor refere-se a supostos resultados obtidos por Coulomb a partir do manuseio do aparato. Assinala:

Em 1784, Coulomb iniciou uma série de cuidadosos experimentos, utilizando uma balança de torção muito sensível, por ele projetada, para descobrir a relação entre o módulo da força de interação entre os corpos carregados eletricamente e a distância entre eles, e concluiu que a força é inversamente proporcional ao quadrado da distância (p. 36).

Igualmente a outros autores, considera que a balança de torção foi utilizada pra aferir a força de interação entre corpos eletrizados. Além disso, apesar da imagem do aparato ter sido classificada como fotografia e alguns dos constituintes do aparato serem representados separadamente, não os mobiliza através do texto, tampouco as etiquetas verbais associadas.

A partir das considerações anteriores, a abordagem textual sobre a representação imagética do livro $\mathrm{L}_{6}$, não corrobora com uma descrição do aparato, tampouco dos procedimentos experimentais e resultados obtidos por Coulomb. Assim, classificamos a relação texto-imagem como conotativa.

\section{VI.7 Análise das abordagens do livro $L_{7}$}

No livro $\mathrm{L}_{7}$ encontra-se uma representação imagética da balança elétrica de Coulomb (Imagem G). No tocante ao grau de iconicidade, classificamos como desenho figurativo. Apesar desta classificação, vários constituintes do aparato não estão representados, por exemplo, a escala e o ponteiro do micrômetro localizados na extremidade superior do tubo central; a graduação na escala da fita em torno do cilindro da base; a esfera fixada a uma haste isolante, com a qual se eletriza a esfera localizada na haste vertical, no interior do cilindro.

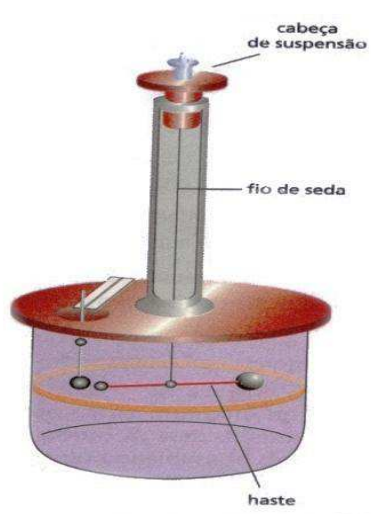

Imagem $G$ - Representação imagética da balança elétrica no livro $L_{7}$.

\footnotetext{
${ }^{3} \mathrm{~A}$ Imagem $\mathrm{F}$ não está representada, porém, é semelhante à imagem $\mathrm{C}_{1}$.
} 
Semelhantemente a outras representações, na imagem G, o plano em forma de círculo, na extremidade direita da haste horizontal localizada no interior do cilindro da base é representado por uma esfera. Além disso, na haste vertical inserida na cavidade esquerda da cobertura do cilindro da base, a qual é sustentada pela pinça, contém duas esferas fixas, ao invés de uma, conforme a representação referência. Possivelmente, foi uma tentativa de representar a esfera fixada em uma haste isolante, a qual eletriza a esfera localizada no interior do cilindro, fixada a haste vertical que é sustentada pela pinça. Mas, inviabilizaria o funcionamento do aparato experimental.

Destacamos ainda na imagem $\mathrm{G}$ incompatibilidades nas dimensões físicas de alguns componentes. Por exemplo, a altura do tubo central e a do cilindro da base estão desproporcionais em relação à imagem referência e a largura da base do cilindro é superior à própria altura. A haste horizontal e o fio de suspensão possuem dimensões semelhantes, o que comprometeria a sensibilidade do instrumento à força de repulsão entre as esferas.

Associadas a imagem G, encontram-se três etiquetas verbais, que classificamos como nominativas. Uma delas, nomeando o fio de sustentação como sendo de seda. No entanto, no aparato original, este fio é de prata, visando suportar a tração devida à força de repulsão, quanto o peso da haste horizontal.

Sobre a balança elétrica, os autores do livro $\mathrm{L}_{7}$ assinalam:

O físico francês Charles Coulomb (1738-1806), utilizando uma balança de torção, comprovou experimentalmente a hipótese segundo a qual as forças elétricas que objetos carregados exercem variam inversamente com o quadrado da distância. Coulomb também estabeleceu a relação entre a intensidade da força elétrica e a quantidade de cargas. Para isso, pegou duas esferas metálicas de mesmo raio, uma neutra e outra carregada, e encostou uma na outra. Após o contato, carga excedente redistribui-se igualmente entre as duas esferas. Coulomb mediu a intensidade da força elétrica produzida pelas esferas (agora com $1 / 2$ de cargas), encostando uma das esferas em outra como mesmo tamanho e estando neutra. Agora, com 1/4 das cargas, mediu novamente a intensidade da força, e assim sucessivamente. Coulomb constatou que a intensidade da força era proporcional à quantidade de cargas (p.78).

Igualmente a outras menções, refere-se a balança elétrica como sendo balança de torção. Descrevem especificidades físicas relacionadas às esferas eletrizadas no interior do cilindro da base, porém não discorrem sobre a razão de ser das especificidades das esferas, tampouco referem-se aos mecanismos decorrentes das interações entre essas. Priorizam resultados gerais supostamente decorrentes das interações entre essas esferas.

No texto anterior, note-se que as etiquetas verbais sequer são mencionadas. Apesar do texto se referir a interação entre esferas eletrizadas, não relaciona com as esferas representadas na imagem. Logo, classificamos a relação texto-imagem como conotativa. 


\section{VI.8 Análise das abordagens do livro $L_{8}$}

No livro $\mathrm{L}_{8}$ encontra-se uma representação imagética da balança elétrica (Imagem H). Quanto ao grau de iconicidade, classificamos a mesma como desenho figurativo. Mas, traz incompatibilidades em relação à imagem referência. Uma delas é representação de uma esfera na extremidade direita da haste horizontal, além da ausência de graduação da escala no cilindro da base. Percebe-se ainda que às dimensões do diâmetro da haste horizontal, localizado no interior do cilindro da base, assemelha-se a do fio vertical, que perpassa pelo interior do tubo central. Tal condição comprometeria o funcionamento do aparato no tocante a sensibilidade à repulsão entre as esferas.

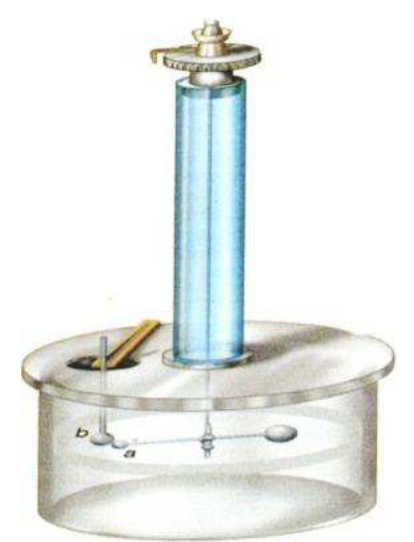

Imagem $\mathrm{H}$ - Representação imagética da balança elétrica no livro $L_{8}$.

Associadas à imagem $\mathrm{H}$, encontram-se duas etiquetas verbais relacionadas às esferas localizadas na extremidade esquerda no interior do cilindro, aqui classificadas como nominativas, mobilizadas na abordagem textual. Os autores assinalam:

Coulomb construiu um aparelho, denominado balança de torção, com o qual ele podia medir diretamente as forças de atração e repulsão entre corpos eletrizados. A imagem $P$ apresenta uma cópia do desenho desta balança, feito pelo próprio Coulomb no relatório enviado à Academia de Ciências. Observe, no desenho, que duas esferas estão equilibradas nas extremidades de uma haste horizontal, suspensa por um fio. A esfera a está eletrizada e uma esfera b, também eletrizada, é aproximada de a. Em virtude da força elétrica que se manifesta entre a e b, a haste gira, provocando uma torção no fio. Medindo o ângulo de torção do fio, Coulomb conseguia determinar o valor da força entre as esferas [...] realizando medidas com as esferas separadas por diversas distâncias, Coulomb verificou que, realmente, a força elétrica era realmente inversamente proporcional ao quadrado da distância entre elas. Além disso, ele concluiu que esta força era proporcional ao produto das cargas elétricas das esferas (p. 35).

Igualmente a outros, nomeiam o aparato como balança de torção. Ao contrário do que afirmam, a balança elétrica registra apenas força de repulsão entre as esferas eletrizadas a e b.

Quanto à relação texto-imagem, apesar da unidade de análise do livro $\mathrm{H}$ referir-se aos constituintes do aparato, tais menções são bastante gerais, sem o detalhamento das respectivas funções nos procedimentos realizados. Mas, pela menção ao aparato, classificamos a relação do texto com a imagem como incorporando uma tendência denotativa. 


\section{VI.9 Análise das abordagens do livro $\mathrm{L}_{9}$}

O livro L 9 traz uma representação imagética da balança elétrica (Imagem I) que, em relação ao grau de iconicidade, classificamos como desenho figurativo mais signos. Contudo, constatamos a ausência de vários constituintes na representação do aparato. São eles: a fita com a escala na base do cilindro; a pinça de sustentação da haste vertical, na qual está fixada a esfera a ser eletrizada $\left(\mathrm{q}_{2}\right)$, como também a haste isolante fixada a uma esfera que eletrizará a esfera $\mathrm{q}_{2}$ (Fig. 4). Na parte superior do cilindro central, não estão representados o ponteiro e a escala do micrômetro. Uma esfera fixada à direita da haste horizontal localizada no interior do cilindro da base, ao invés de um plano circular.

$\mathrm{Na}$ imagem I, alguns componentes não apresen-

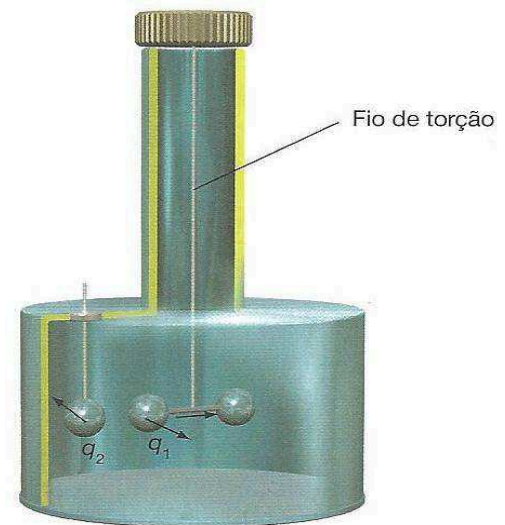

Imagem I - Representação imagética do Livro L9. tam dimensões com proporcionalidade física. Por exemplo, o diâmetro das esferas é bastante extenso em relação ao comprimento da haste horizontal, o que diminuiria a precisão do aparato, haja vista que o torque produzido pela interação entre as esferas $q_{1}$ e $q_{2}$ depende do comprimento da haste que as separa. Além disso, na imagem referência, a altura do cilindro central é aproximadamente o dobro da altura do cilindro da base.

Associadas à imagem I, encontram-se cinco etiquetas verbais. Uma desta é nominativa, referente ao fio que suspende a haste horizontal, relacionando-o com a propriedade da torção associada ao mesmo, deixando implícita a sua natureza. As duas etiquetas verbais $\mathrm{q}_{1} \mathrm{e}$ $\mathrm{q}_{2}$ são classificadas como nominativas, porém, como o texto não as mencionam, a priori, não é possível afirmar se são relacionadas à natureza das cargas ou se as esferas. Mas, com as duas outras etiquetas verbais, representadas por setas, são classificadas com relacionais, pois denotam o sentido da força de repulsão entre as duas esferas, é possível inferir que $\mathrm{q}_{1}$ e $\mathrm{q}_{2}$ estejam relacionadas à natureza da eletrização das esferas.

$\mathrm{Na}$ abordagem textual sobre a balança elétrica, os autores do livro $\mathrm{L}_{9}$ assinalam:

No século XVIII, o cientista Charles Augustin Coulomb (1736-1806) preocupou-se em avaliar as características matemáticas da força de interação entre dois corpos eletrizados. Para tanto, realizou uma série de experimentos com cargas pontuais, em que variou tanto a intensidade das cargas quanto a distância entre elas. Usando uma balança de torção, Coulomb percebeu que, a certa distância fixa, a força de interação entre corpos eletrizados dependia da intensidade das cargas elétricas. Quanto maior fosse a carga elétrica, maior era também a força de interação entre os corpos. Coulomb percebeu ainda que, à medida que aumentava a distância entre duas cargas, diminuída a força de interação entre elas. Assim, se cargas maiores implicavam forças de maior intensidade, e se maiores distâncias entre as cargas implicavam menores módulos de forças de interação, o problema que Coulomb precisava resolver consistia em encontrar a relação matemática de dependência entre 
as grandezas "força de interação", "distância entre cargas" e "intensidade das cargas". E ele encontrou (p. 39).

No texto anterior, os autores relatam o que seria os possíveis resultados pretendidos por Coulomb utilizando a balança elétrica. Porém a forma como os resultados foram obtidos estão distorcidos de acordo com os originais. A construção da balança de torção ocorreu antes da balança elétrica. Além disso, Coulomb não analisou as características matemáticas da força de interação elétrica e nem a relação da mesma com a intensidade das cargas presentes nos corpos. Coulomb buscava de fato era uma relação quantitativa da força com a distância entre corpos eletrizados, haja vista que não podia determinar a quantidade de carga das esferas.

Outra distorção da menção anterior relaciona-se a afirmativa de que, nos procedimentos experimentais, Coulomb aumentava a distância entre os corpos carregados para observar a redução da força. No entanto, nos relatos de Coulomb, à distância entre as esferas eram reduzidas para se observar o aumento da força de interação entre elas. Por outro lado, o texto não se refere aos componentes do aparato em consonância com os procedimentos realizados. Assim, classificamos a relação texto-imagem do livro $\mathrm{L}_{9}$ como incorporando uma tendência conotativa, requerendo do leitor um certo conhecimento sobre o aparato.

No texto do livro $\mathrm{L}_{9}$, as etiquetas verbais sequer são mencionadas, logo, não corroboram com o entendimento sobre a constituição do aparato ou o funcionamento do mesmo.

\section{VI.10 Abordagens das abordagens do livro $L_{10}$}

$\mathrm{O}$ livro $\mathrm{L}_{10}$ traz uma representação imagética referente à balança elétrica (Imagem J), classificada como fotografia, uma reprodução da referência ${ }^{4}$. As etiquetas verbais também são as da referência, todas nominativas.

$\mathrm{Na}$ abordagem textual sobre a balança elétrica, os autores do livro $\mathrm{L}_{10}$ assinalam:

Entre os estudos realizados por Coulomb sobre atrito, Eletricidade, Eletromagnetismo etc., talvez o que tenha obtido maior projeção seja o que ele realizou também com uma balança de torção, inventada pelo inglês John Mitchell (1724 - 1796).

Nesse experimento, Coulomb chegou à lei que leva o seu nome e estabelece que: "a intensidade da resultante das forças de interação entre as partículas carregadas $e$ letricamente é diretamente proporcional à quantidade de cargas das partículas em estudo e inversamente proporcional ao quadrado da distância entre elas". Com um metro de altura, a balança de Coulomb é constituída por um tudo de vidro cilíndrico apoiado em outro recipiente apoiado de vidro cilíndrico mais largo e oco. $\mathrm{Na}$ parte superior, existe um micrômetro e um sistema de fixação do fio de prata. Esse fio passa por dentro do tubo mais estreito e tem preso à sua extremidade inferior um peso e uma haste horizontal. A haste tem em uma das extremidades uma bola de medula de sabugueiro (com diâmetro $=5 \mathrm{~mm}$ ), e, na outra, um disco de papel cuja função é diminuir as oscilações e equilibra a haste.

\footnotetext{
${ }^{4}$ Devido ao espaço, a Imagem $\mathrm{J}$ não se encontra representada, porém, é semelhante a imagem $\mathrm{C}_{1}$.
} 
No interior do cilindro inferior há outro fio que suporta uma bola fixa e igual à anterior. Nesse cilindro também é colocado um papel com escala graduada (p. 42).

Já discutido anteriormente, foi através da balança elétrica de repulsão Coulomb obteve os dados experimentais referentes à relação da força com a distância entre as esferas eletrizadas e não com a quantidade de carga nas esferas, conforme mencionam os autores.

Diferentemente dos demais livros, os autores mencionam alguns constituintes da balança elétrica, tal como descrita por Coulomb, a exemplo da escala graduada, fixada ao cilindro da base da balança; a esfera fixada à haste vertical, além de explicitar a natureza do material constituinte das esferas. Uma peculiaridade na abordagem do livro $\mathrm{L}_{10}$ é que se reportam ao disco de papel na extremidade direita da haste horizontal, como também a sua função.

Apesar da menção dos constituintes do aparato experimental, interpretamos que os autores não mobilizam satisfatoriamente a relação entre os elementos constituintes da balança elétrica presentes na representação com a descrição textual da função dos mesmos durantes os testes experimentais, os quais levaram aos resultados alcançados por Coulomb. As etiquetas verbais sequer são mencionadas no texto. Assim, classificamos a relação texto-imagem como conotativa.

No Quadro II encontra-se uma síntese das abordagens dos livros didáticos no tocante a quantidade de imagens, o grau de iconicidade, etiquetas verbais e relação texto-imagem apresentados em cada livro didático analisado.

Quadro II - Síntese das abordagens dos livros didáticos.

\begin{tabular}{|c|c|c|c|c|}
\hline Livro & $\begin{array}{c}\text { Quantidade } \\
\text { de Imagens }\end{array}$ & Grau de Iconicidade & Etiquetas Verbais & $\begin{array}{c}\text { Relação Texto- } \\
\text { Imagem } \\
\text { Conotativa }\end{array}$ \\
\hline $\mathbf{L}_{\mathbf{1}}$ & 1 & Desenho figurativo & 2 Nominativas & (10 Nominativas (B1); \\
3 Nominativas e 1 \\
relacional (B2); 3 \\
$\mathbf{L}_{\mathbf{2}}$
\end{tabular}




\section{Considerações finais}

Em três livros didáticos encontra-se a representação com grau de iconicidade fotografia (Imagens $\mathrm{C}_{1}, \mathrm{~F}, \mathrm{~J}$ ), a qual visa reproduzir a realidade (PERALES; JIMÉNEZ, 2002). Porém, a relação de todas essas imagens com o texto é conotativa ou sem correspondência com a imagem.

Em sete livros didáticos encontram-se representações imagéticas sobre a balança elétrica com grau de iconicidade desenho figurativo (Imagens A, B ${ }_{1}, C_{2}, \mathrm{D}, \mathrm{E}, \mathrm{G}, \mathrm{H}$ e I). Apesar de tratar-se de uma representação que imita a realidade (PERALES; JIMÉNEZ, 2002), existem incoerências relacionadas às dimensões físicas do aparato (Imagens B1, E, H e I). Além disso, vários componentes foram suplantados nas representações, tais como a pinça que fixa a haste vertical no interior do cilindro da base (Imagens $A, B_{1}, C_{2}, J$ ), a escala e ponteiro do micrômetro (Figuras A, $\mathrm{C}_{2}, \mathrm{G}$ e I), a haste com a esfera (Fig. 4) que eletriza a esfera fixada à haste vertical no interior do cilindro da base da balança (Imagens A, B $1, C_{2}, D, E, G, H$ e I). Sem essa haste com a esfera, não se inicia o de funcionamento da balança. Assim questionamos qual o propósito das imagens, senão explicar os processos que propiciaram Coulomb a empreender certas afirmativas ou mesmo o funcionamento do aparato. Apenas no texto do livro L1 esta esfera é mencionada, apesar de não representada na imagem correspondente (Imagem A).

Em várias representações imagéticas, o plano de papel localizada na extremidade direita da haste horizontal da balança (Fig. 1) é representado por uma esfera (Imagens $A, C_{2}, C_{3}$, $\mathrm{C}_{4}, \mathrm{D}, \mathrm{E}, \mathrm{G}, \mathrm{H}$ e I). Em algumas representações, existem etiquetas verbais nominativas, realçando a representação da esfera (imagens $\mathrm{B}_{1}, \mathrm{~B}_{2}$ e $\mathrm{B}_{3}$ ). A imagem B2, além da etiqueta verbal nominativa, o texto refere-se à suposta esfera. Apenas o texto da imagem $\mathrm{J}$, classificada como fotografia, refere-se a um plano de papel que se presta para equilibrar a estrutura.

Apesar da ausência de representação dos constituintes físicos do aparato experimental corroborar com a desarticulação da relação texto-imagem, uma representação imagética com alto grau de iconicidade não significa a sua mobilização pelo texto. Notemos que, mesmo as imagens com grau de iconicidade fotográfica, não articulam coerentemente a imagem com o texto e pouco mobilizam as etiquetas verbais. Assim, a imagem distancia-se da possibilidade de funcionar como um elemento que propicia um melhor entendimento do conceito, conforme defende Cassiano (2002).

A desarticulação texto-imagem nas abordagens sobre a balança elétrica contraria a defesa de Martins, Gouvêa e Piccinini (2005), para as quais essa articulação contribuiria para a compreensão dos conceitos científicos, bem como a imagem aclarando as informações textuais, conforme Duchastel e Waller (1979). Ou seja, na presente análise, a função da utilização das imagens sobre a balança elétrica distancia-se das análises de Valladares e Palacios (2002), onde as imagens propiciam convencimento sobre a linguagem verbal.

As análises aqui realizadas aproximam-se da afirmação de Belmiro (2000) de que a abordagem imagética nos livros didáticos pouco completa o texto, quando não lhe retira o 
sentido. Certamente, este nível de desarticulação texto-imagem está além da ausência de alguns componentes físicos da balança elétrica, haja vista as desarticulações texto-imagem em relação às representações com nível de iconicidade fotografia $\left(\mathrm{C}_{1}, \mathrm{~F}, \mathrm{~J}\right)$. Notamos nestas que a abordagem textual pouco mobiliza as representações imagéticas, priorizando menções a conclusões elaboradas por Coulomb a partir de prováveis resultados experimentais obtidos com o aparato em análise. Logo, as representações imagéticas sobre a balança elétrica, distanciam-se da perspectiva de mediarem uma compreensão sobre as ideias científicas relacionadas, conforme defendem Martins, Gouvêa e Piccinini (2005).

As constatações anteriores certamente prestam-se como alerta tanto aos autores dos livros didáticos no tocante ao uso das imagens, bem como aos elaboradores de critérios de avaliação dos livros didáticos de ciências. Porém, tais considerações distanciam-se do propósito da presente investigação.

\section{Referências}

APPLE, M. As políticas culturais e o texto. In: (Ed.) Conhecimento oficial. A educação democrática em uma era conservadora. 2 ed. Petrópolis, RJ: Editora Vozes, 1997. cap. 3, p. 71-96.

ASSIS, A. K. T. Os fundamentos experimentais e históricos da Eletricidade. Montreal: Apeiron, 2010. 274 p.

BARTHES, R. O óbvio e o obtuso: ensaios críticos III. Rio de Janeiro: Nova Fronteira, 1990. 284 p.

BELMIRO, C. A. A Imagem e suas formas de visualidade nos livros didáticos de Português. Educação e Sociedade, v. 21, n. 72, p. 11-31, 2000.

BERNAL, J. D. La proyeccion del hombre. Historia de la Fisica Classica. Madrid: Editora Siglo Veintiuno, 1975.

BOGDAN, R. C.; BIKLEN, S. K. Investigação qualitativa em educação. Uma introdução à teoria e aos métodos. Porto: Porto Editora, 1994.

BONAZZI, M.; ECO, U. Mentiras que parecem verdades. São Paulo: Summus, 1980. 132 p.

CAMPANARIO, J. M. Qué puede hacer un profesor como tú o um alumno como el tuyo con un libro de texto como éste? una relación de actividades poco convencionales. Enseñanza de las Ciencias, v. 19, n. 3, p. 351-364, 2001. 
CARNEIRO, M. H. S. As imagens no livro didático. In: ENCONTRO NACIONAL DE PESQUISA EM ENSINO DE CIÊNCIAS, 1, 1997, Águas de Lindoia, Atas ... Porto Alegre, Instituto de Física da UFRGS, 1997. p. 366-376.

CASSIANO, M. S. Análise de imagens em livros didáticos de física. 2002. 126 f. Dissertação (Mestrado em Educação) - Faculdade de Educação, UnB, Brasília.

COUlOMB, C. A. (1785) “Premier Mémoire sur l'Électricité et le Magnétisme. Construction $\&$ usage d'une Balance électrique, fondée sur la propriété qu'ont les Fils de métal, d'avoir une force de réaction de Torsion proportionnelle à l'angle de Torsion" Mémoires de l'Académie Royale des Sciences, Paris, 1788. p. 569-577.

COUTINHO, F. A. et al. Análise do valor didático de imagens presentes em livros de biologia para o ensino médio. Revista Brasileira de Pesquisa em Educação em Ciências, v. 10, n, 3, 2010.

DUCHASTEL, P.; WALLER, R. Pictorial illustration instructional texts. Educational technology, nov., p. 20-25, 1979.

FORBES, R; DIJKSTERHUIS, E. A history of science and tecnology: the eightheenth and ninetheenth centuries. London: Pelican Books, 1963.

FRANCISCO JÚNIOR, W. E. Analogias em livros didáticos de Química. Um estudo das obras aprovadas pelo Plano Nacional do Livro Didático Para o Ensino Médio 2007. Ciência \& Cognição, v. 14, n. 1, p. 121-143, 2009.

GIBIN, G. B.; KIILL, K. B.; FERREIRA, L. H. Categorização das imagens referentes ao tema equilíbrio químico nos livros aprovados pelo PNLEM. Revista Eletrônica de Enseñanza de las Ciencias, v. 8, n. 2, p. 711-721. 2009. Disponível em:

$<$ http://reec.uvigo.es/volumenes/volumen8/ART18_Vol8_N2.pdf>. Acesso em: 15 jan. 2013.

GILBERT, W. The Magnete. New York: Dover Publications, 1958.

LANGHI, R.; NARDI, R. Ensino de astronomia: erros mais conceituais mais comuns presentes em livros didáticos de ciências. Caderno Brasileiro de Ensino de Física, v. 24, n. 1, p. 87-111, abr 2007.

MARTINS, I.; GOUVÊA, G.; PICCININI, C. L. Aprendendo com imagens. Ciência e Cultura, v. 57, n. 4, p. 38-40, 2005.

MEDEIROS, A.; MEDEIROS, C. Questões epistemológicas nas iconicidades de representações visuais em livros didáticos de Física. Revista Brasileira de Pesquisa em Ensino de Ciências, v. 1, n, 1, (sem paginação), 2001. 
OSTERMANN, F.; RICCI, T. F. Relatividade restrita no ensino médio: contração de LorentzFitzgerald e aparência visual de objetos relativísticos em livros didáticos de Física. Caderno Brasileiro de Ensino de Física, v. 19, n. 2, p.176-190, 2002.

PERALES, F. J.; JIMÉNEZ, J. D. Las ilustraciones en la enseñanza-aprendizaje de las ciencias. Análisis de libros de texto. Enseñanza de las Ciencias, v. 20, n. 3, p. 369-386, 2002.

PIMENTEL, J. R. Livros didáticos de ciências: a física e alguns problemas. Caderno Catarinense de Ensino de Física, v. 15, n. 3, p. 308-318, 2006.

ROLLER, D., ROLLER, H. D. The developmente of the concept of electric charge. In: CONANT, J. B. Harvard Case Studies in Experimental Science. Havard: Havard University Press, 1957. p. 541-639.

SEBATA, C. E.; SANTOS, W. L. P.; CARNEIRO, M. H. S. As imagens em textos didáticos de temas sociais em livro didático de Química: análise de seu papel pedagógico. In: ENCONTRO NACIONAL DE PESQUISA EM EDUCAÇÃO EM CIÊNCIAS, 5, 2005, Bauru. Atas... Bauru: ABRAPEC, 2005, 1 CD-ROM.

SILVA, H. C. et al. Cautela ao usar imagens em aulas de Ciências. Ciência e Educação, v. 12, n. 2, p. 219-233, 2006.

VALLADARES, J. D. J.; PALACIOS, F. J. P. La evidencia experimental através de la imagen de los libros de texto de Física Y Química. Revista Electrónica de Enseñanza de las Ciencias, v. 1, n. 2, p. 114-129, 2002. Disponível em:

<http://www.webs.uvigo.es/reec/volumenes/volumen1/REEC_1_2_5.pdf > Acesso em: 18 jan. 2013. 